\title{
Students' Performance in Microeconomics: Evidence from Vavuniya Campus, Sri Lanka
}

\author{
Thayaparan, A.* and Gunathilaka, G. Y. N. \\ Vavuniya Campus of the University of Jaffna, Sri Lanka \\ *aruppillaithayaparan@yahoo.com
}

\begin{abstract}
This study examined the factors affecting the performance of undergraduate students in microeconomics at Vavuniya campus, Sri Lanka. For this purpose, a survey is conducted to collect the data using a sample of 85 students, who enrolled in microeconomics during their first year first semester in the academic year 2015/2016. The data on students' performance in microeconomics measured in terms of their grades they obtained for the subject, demographic characters with family background and educational factors gathered from the questionnaire. The collected data was analyzed using frequency, chi- square test, ordered probit regression and marginal effects in the study. Frequency of the students' grades revealed that, nearly $59 \%$ of them got grade B while $9.4 \%$ of them received grade A and $4.7 \%$ of the students received grade D. Chi - square test found that family stress and frequency of the study habits significantly associates with the students' grades in the subject while the grade obtained in general English in G.C.E (A/L) and the usage of library facilities were less associated in the study. Results of ordinal probit model suggested that among the variables related to demographic characteristics with family background, gender and family stress are the good predictors of student performance in microeconomics whereas among educational factors allocation of time, economics as a subject taken by the students in G.C.E (A/L), mathematics knowledge and the usage of library facilities are the other best predictors in students' performance in the subject.
\end{abstract}

Keywords: Demographic characteristics, Educational factors, Ordered probit model, Students' performance

\section{Introduction}

Higher education plays a pivotal role in developing human capital in each and every country in the world because it accelerates the economic growth through knowledge, skills and attitude changes. Expenditure on education is a long-term strategy to achieve a variety of goals from ranging from economic development through poverty alleviation, reduction of inequality, improvements in health, good governance and institutional development. At the macro level, education positively contributes to economic development via building human capital and it has been accepted as an engine of economic growth across countries [Breton, 2015]. Schools, colleges and universities are meaningless without students because they are the backbone of an education system in a country. The overall development of any country is directly linked with student academic performance [Muhammedhussen, 2016].

According to Ali et al. (2013) student performance is generally viewed as a product of socioeconomic, psychological and environmental factors and the factors are expected to vary from place to place. Identifying the factors that influence students' performance is not a simple task. It has been the subject of ongoing debate among educators, academics, and policymakers [Sarwar, 2012]. Understanding the Johns et al. (2007) based on the sample of 427 students conducted a study on an ordered probit model for understanding student performance in operations management. Results of the study reveal that higher Grade Point Average (GPA) causes to obtain better grade in operations management which indicates that when the GPA increased by one unit it makes probability to get grade A or B by $59.8 \%$ and $4.25 \%$ respectively. Further, results highlighted that the probability of getting poorer grades of $\mathrm{C}$ and $\mathrm{D}$ was reduced by $50.7 \%$ and $13.3 \%$ respectively. Student's performance in operations management was not significant with gender, term in which the course was taken, and performance in various prerequisite courses. Status and determinants of academic performance of students is crucial for successful and effective intervention to bring quality of education in a country. The academic 
performance of students in universities is a concern in order to evaluate the quality of teaching and learning in higher education.

Various researchers conducted studies in different parts of the globe to understand and identify the real determinants of university students' academic performance using different subject areas. The knowledge of determinants of students' performance on subject helps to identify the effective and efficient interventions in order to increase their success. Vavuniya Campus of the University of Jaffna offers both microeconomics and macroeconomics as a compulsory course unit in the first year for the Bachelor of Business Management degree program. Students are entering the university as freshers with the different backgrounds and they are struggling to adopt to the university culture. Due to that compared to the performance in macroeconomics, students have less performed in microeconomics. However, from first year second semester onwards students are acquainted the university culture and thus they are gradually improving in academic performance. The success or failure in microeconomics module directly impacts on the number of years students take to complete their degree and if any student fails to obtain the particular GPA in microeconomics they were not eligible to undergo the Business Economics specialization. Because of the above reasons rather than selecting macroeconomics, selection of microeconomics is more appropriate in order to implement necessary strategies to increase the students' performance in Vavuniya Campus.

There is a lacuna in literature with regards to the studies in relation to factors determining the performance of undergraduate students and more specifically the performance of the students those who are pursuing economic courses in their undergraduate program. However, it is questionable to what extend the results of previous studies are applicable to understand the students' performance in microeconomics. There is no any comprehensive and systematic study carried out in relation to the students' academic performance of Vavuniya Campus particularly in relation to the subject of microeconomics. Hence, the researchers initiated a study to fill the lacuna in literature.

The findings of the study will guide the undergraduate students in what ways they need to be improving their study habits and how they allocate the time among various subjects to get better results and grades in microeconomics. The lecturer who is teaching the particular subject can understand the students' performance and their problems that they are facing and based on that they can decide student-oriented approaches to improve the teaching methods effectively. Senior academics also will be guided on what aspects should be emphasized in the education systems including syllabus and curriculum to improve the present situation in the campus. Finally, the findings of this study may help to identify the effective and efficient interventions in order to increase the students' performance in microeconomics as well as academic staff also can understand the performance of the students.

This study aims to understand the association between the demographic characteristics including family background and educational factors with the students' performance in microeconomics. Further, the impact of demographic characteristics with family background and educational factors on the performance in the microeconomics are also examined in this study.

McCarty et al. (2006) identified the factors that influence student learning in college macroeconomics and microeconomics courses. Results of the econometrics analysis reveals that gender, matching instructor and student gender, and GPA were significantly impact on the performance in principles of microeconomics and macroeconomics while, student achievement from college entrance exam scores and class size were not significant. Further, results highlighted that student improvement was significantly higher in macro than in microeconomics.

Johns et al. (2007) based on the sample of 427 students conducted a study on an ordered probit model for understanding student performance in operations management. Results of the study reveal that higher GPA causes to obtain better grade in operations management which indicates that when the GPA increased by one unit it makes probability to get grade A or B by $59.8 \%$ and $4.25 \%$ respectively. Further, results highlighted that the probability of getting poorer grades of $\mathrm{C}$ and $\mathrm{D}$ was reduced by $50.7 \%$ and $13.3 \%$ respectively. Student's performance in operations management was not significant with gender, term in which the course was taken, and performance in various prerequisite courses. 
Mushtaq \& Khan (2012) identified communication, learning facilities and proper guidance had a positive impact on the student performance and the family stress had a negative impact on the student performance. Pretorius et al. (2009) found that matriculation exemption, students' performance in mathematics, language of instruction, success of passing assignments, effort of students on their success had an impact on student performance in introductory microeconomics at an African open and distance learning institution and gender as an insignificant determinant.

Muhammedhussen (2016) conducted a study in order to identify the determinants of economics students' academic performance at Jimma University, Ethiopia. The study applied independent t-tests, Pearson correlation and Tobit model. University entrance exam score, family economic situation, sleep time and habit of study were identified as the main determinants of students' academic performance where, sex, residential place, study time and recreation time were found insignificant.

Sriyalatha (2016) examined the factors affecting academic performance at the Faculty of Management Studies and Commerce, University of Sri Jayewardenepura in Sri Lanka. Results of multiple regression analysis revealed that level of mothers' education, English knowledge of the students and higher levels of attendance for lectures have positive effect towards their academic performance.

Questionnaire survey was conducted to collect primary data among the students during the academic year 2015/2016 who studied microeconomics in their first year first semester at Vavuniya Campus. For this purpose, 100 responds were selected by using simple random sampling method. All the questionnaires were checked and incomplete were rejected to ensure the reliability of the sample. As a result, only 85 questionnaires were relevant and it considered as the sample of the study.

Demographic profile of the respondents, educational factors and distribution of grades among male and female students were analyzed by using frequency. Further, this study applied chisquare test to identify the association between family stresses, allocation of time for study, grade in general English and usage of library with students' performance in microeconomics. Since, the outcome variable is an ordinal in nature the study applied ordered probit model to investigate the impact of demographic characteristics and educational factors on students' performance. The impact of each explanatory variable on the outcome variable was measured in terms of probability by using marginal effects.

The dependent variable is the students' performance in microeconomics measured by four different grades such as A, B, C and D whereas demographic characteristics of the students and educational factors were considered as explanatory variables to predict the probabilities of receiving different grades in microeconomics. The general forms of the models for the two sets of explanatory variables are given below.

\section{Model 1:}

Ordered probit regression for demographic characteristics and family background of the students

$$
Y=\beta_{0}+\beta_{1} X_{1}+\beta_{2} X_{2}+\beta_{3} X_{3}+\epsilon
$$

where

$Y=$ Grades for microeconomics subject which is categorized as, 1 for $\mathrm{D}, 2$ for $\mathrm{C}$, 3 for $\mathrm{B}$ and 4 for $\mathrm{A}$

$X_{1}=$ Gender is as a dummy variable coded as, 1 for male and 0 for female

$X_{2}=$ Family stress is another dummy variable coded as 1 for yes and 0 for no

$X_{3}=$ Family members with management degree is also measured by dummy variable coded as 1 for yes and 0 for no

$\beta_{0}=$ Constant

$\beta_{1}, \beta_{2}$ and $\beta_{3}$ represent the coefficient of each independent variable respectively.

$\epsilon=$ Error term which is normally distributed with a mean of zero and standard deviation of one

\section{Model 2:}

Ordered probit regression for educational background of the students

$$
\begin{array}{r}
Y=\beta_{0}+\beta_{1} X_{1}+\beta_{2} X_{2}+\beta_{3} X_{3}+ \\
\beta_{4} X_{4}+\beta_{5} X_{5}+\beta_{6} X_{6}+\epsilon
\end{array}
$$

where 
$Y=$ Grades for microeconomics subject which is categorized as, 1 for D, 2 for C, 3 for $\mathrm{B}$ and 4 for $\mathrm{A}$

$X_{1}=$ Grades for microeconomics subject which is categorized as, 1 for D, 2 for C, 3 for $\mathrm{B}$ and 4 for $\mathrm{A}$

$X_{2}=$ Level of attendance coded as 1 for very good, 2 for good, 3 for average and 4 for low

$X_{3}=$ Microeconomics taken as a subject in G.C.E (A/L) coded as 1 for yes and 0 for no

$X_{4}=$ Mathematics knowledge coded as 1 for poor, 2 for average and 3 for good

$X_{5}=$ Usage of library facilities coded as 1 for never, 2 for sometimes and 3 for regular

$X_{6}=$ Available of own text books coded as 1 for yes and 0 for no

$\beta_{0}=$ Constant

$\beta_{1}, \beta_{2}, \beta_{3}, \beta_{4}, \beta_{5}$ and $\beta_{6}$ represent the coefficient of each independent variable respectively.

$\epsilon=$ Error term which is normally distributed with zero mean and standard deviation of one

Table 1: Frequency demographic characteristics and family background

\begin{tabular}{lcc}
\hline Variables & Frequency & Percentage (\%) \\
\hline Gender & & \\
$\quad$ Male & 27 & 31.8 \\
$\quad$ Female & 58 & 68.2 \\
Family stress & & \\
$\quad$ Yes & 19 & 22.4 \\
$\quad$ No & 66 & 77.6 \\
Family members & & \\
with management & & \\
degree & & \\
Yes & 17 & 20 \\
No & 68 & 80 \\
\hline
\end{tabular}

Source: Authors' calculation, 2018/2019

\section{Results and Discussion}

The collected data from 85 students were analyzed by using frequency, chi-square test, ordered probit regression model and marginal effects.

\section{Students' profile and their academic performance in microeconomics}

The selected 85 students were analyzed using frequency statistics and its results show that, $68.2 \%$ of the students were females while $31.8 \%$ of them were males. About $22 \%$ of the students were facing stress problems from their family and $78 \%$ of them did not have that problem in the sample.

The results in table 1 revealed that, majority $(80 \%)$ of the family members do not have management degree and only $20 \%$ of them have.

Frequency of time allocated by the students for studies were shown in table 2 and according to that, very few students have spent more than two hours to study in microeconomics and majority of them spent less than two hours per day. Around 26\% of the students studied on daily and $39 \%$ of them studied during the study leave period.

The frequency of attendance for lectures revealed that $12 \%$ of the students attended on average while $31 \%$ of them have very good attendance. More than $50 \%$ of the students maintained good attendance.

About $72 \%$ of the students studied economics as one of the subjects in General Certificate of Education Advanced Level $\langle$ G.C.E (A/L) $\rangle$ and 59\% of them have average knowledge in mathematics. $4.7 \%$ of the students never utilized the library facilities and $5.9 \%$ of them used it regularly for their studies indicating that the students have less interest to utilize the library.

Students' performance in microeconomics subject was measured in grades A, B, C and D using frequency and the results were given in table 3 .

According to table 3 , it represents that only $4.7 \%$ of the students got grade D and $9.4 \%$ of them got grade A. It implies that, students' performance in the microeconomics subject was not much bad and also not much too high. Majority of their performance belong to grade B followed by grade $\mathrm{C}$ in the selected samples.

Academic performance in microeconomics subject across male and female students was examined using cluster bar chart shown in figure 1 .

Figure 1 depicts that, among male students no one got grade D but $4.71 \%$ of the females got grade D. However, compared to male students, higher percentages of grades A and B received 
Table 2: Frequency of educational background of the students

\begin{tabular}{lcc}
\hline Variables & Frequency & Percentage (\%) \\
\hline Allocation of time & & \\
$\quad$ Less than 2 hours per day & 75 & 88.2 \\
$\quad$ More than 2 hours per day & 10 & 11.8 \\
& & \\
Patterns of study & 22 & 25.9 \\
$\quad$ Daily & 30 & 35.3 \\
$\quad$ Mostly before the assignments & 33 & 38.8 \\
$\quad$ During study leave time & & \\
& & \\
Attendance of lectures & 26 & 30.6 \\
$\quad$ Very good & 49 & 57.6 \\
$\quad$ Good & 10 & 11.8 \\
$\quad$ Average & & \\
Economics as one of the subjects in G.C.E (A/L) & 61 & 71.8 \\
$\quad$ Yes & 24 & 28.2 \\
$\quad$ No & & \\
Mathematics knowledge & 10 & 11.8 \\
$\quad$ Poor & 50 & 58.8 \\
$\quad$ Average & 25 & 29.4 \\
$\quad$ Good & & \\
Usage of library & 4 & 4.7 \\
$\quad$ Never & 76 & 89.4 \\
$\quad$ Some times & 5 & 5.9 \\
$\quad$ Regularly & & 70.6 \\
Having own text books & 60 & 29.4 \\
$\quad$ Yes & 25 & \\
$\quad$ No & & \\
\hline
\end{tabular}

Source: Authors' calculation, 2018/2019

Table 3: Distribution of grades in microeconomics

\begin{tabular}{ccc}
\hline Grades & Frequency & Percentage (\%) \\
\hline D & 4 & 4.7 \\
C & 23 & 27.1 \\
B & 50 & 58.8 \\
A & 8 & 9.4 \\
\hline
\end{tabular}

Source: Authors' calculation, 2018/2019

by female students revealed that comparatively female students performed well than male students. Findings of Chambers \& Schreiber (2004) were aligned with this study which revealed that the female students perform better than the male students.

Table 4 displays the number of students who have different levels of knowledge in mathematics with or without prior knowledge of economics in G.C.E $(\mathrm{A} / \mathrm{L})$. The number of students who have poor knowledge in mathematics without prior knowledge in economics getting the grades $\mathrm{A}$ and $\mathrm{B}$ is zero clearly indicates that, both knowledge in mathematics and economics are important to obtain higher grades. Further, 19 female students and 10 male students got grade $\mathrm{B}$ who have average knowledge in mathematics with prior knowledge in economics.

A student having a knowledge in mathematics, but he or she doesn't have a prior knowledge in economics during G.C.E (A/L), getting grade A is impossible illustrates that, even if they have mathematics skills, it is not enough to get grade A without the basic knowledge in economics. However, if a student has a good knowledge in mathematics as well as prior knowledge in economics, he or she can easily get $\mathrm{A}$ or $\mathrm{B}$ grades. Thus, the findings suggest that, the 


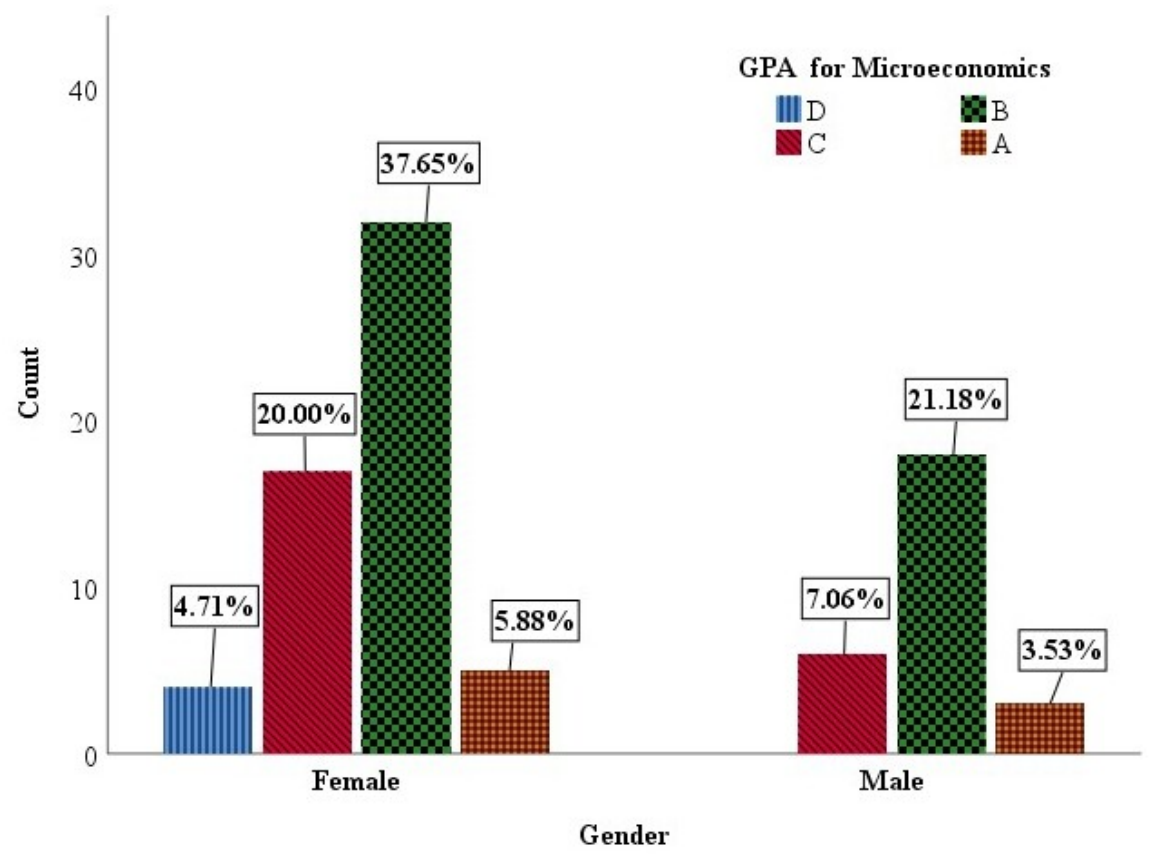

Figure 1: Dispersion of grades among male and female students

Table 4: Number of grades across gender and educational factors

\begin{tabular}{|c|c|c|c|c|c|c|c|c|}
\hline & & & & & & $\mathrm{Gr}$ & des & \\
\hline & & & & & $\mathrm{D}$ & $\mathrm{C}$ & B & A \\
\hline Mathematics & Poor & Economics as a & Yes & Female & 0 & 1 & 1 & 0 \\
\hline knowledge & & subject in $\mathrm{A} / \mathrm{L}$ & & Male & 0 & 2 & 1 & 0 \\
\hline & & & No & Female & 2 & 1 & 0 & 0 \\
\hline & & & & Male & 0 & 2 & 0 & 0 \\
\hline & Average & Economics as a & Yes & Female & 0 & 5 & 19 & 2 \\
\hline & & subject in $\mathrm{A} / \mathrm{L}$ & & Male & 0 & 1 & 10 & 0 \\
\hline & & & No & Female & 1 & 7 & 3 & 0 \\
\hline & & & & Male & 0 & 1 & 1 & 0 \\
\hline & Good & Economics as a & Yes & Female & 0 & 3 & 7 & 3 \\
\hline & & subject in $\mathrm{A} / \mathrm{L}$ & & Male & 0 & 0 & 3 & 3 \\
\hline & & & No & Female & 1 & 0 & 2 & 0 \\
\hline & & & & Male & 0 & 0 & 3 & 0 \\
\hline
\end{tabular}

Source: Authors' calculation, 2018/2019

students who is willing to obtain the best results in microeconomics, they should have a basic knowledge in mathematics and also a prior knowledge in economics.

Another analytical tool is the chi-square test which was also used to test the association between family stress and educational background with performance of the students (table 5). $25 \%$ of the students who suffer from family stress got grade A whereas, $75 \%$ of them got the same grade without family stress. The chi- square value is 0.001 further revealed that, the association between them statistically significant at $1 \%$ level. Similarly, frequency of the study has significantly associated with the grades of the subject at $5 \%$ level and it suggests that, no one who studies only during their study leave period can get an A grade. The students studying daily, have more possibility to get grade $\mathrm{A}$ and no any possibility to get grade D. It is impossible to get grade A for the students who study only during the study leave period. 
Table 5: Results of chi - square test

\begin{tabular}{|c|c|c|c|c|c|c|}
\hline & \multicolumn{4}{|c|}{ Grades } & \multirow[b]{3}{*}{$\chi^{2}$} & \multirow[b]{3}{*}{ Significance } \\
\hline & $\mathrm{A}$ & $\mathrm{B}$ & $\mathrm{C}$ & $\mathrm{D}$ & & \\
\hline \multicolumn{5}{|l|}{ Variables } & & \\
\hline \multicolumn{5}{|l|}{ Family stress } & 16.32 & 0.001 \\
\hline Yes & $25 \%$ & $8 \%$ & $47.8 \%$ & $50 \%$ & & \\
\hline No & $75 \%$ & $92 \%$ & $52.2 \%$ & $50 \%$ & & \\
\hline \multicolumn{5}{|l|}{ Frequency of study } & 14.26 & 0.027 \\
\hline Daily & $75 \%$ & $24 \%$ & $17.4 \%$ & $0 \%$ & & \\
\hline Mostly before the assignments & $25 \%$ & $36 \%$ & $39.1 \%$ & $25 \%$ & & \\
\hline During study leave time & $0 \%$ & $40 \%$ & $43.5 \%$ & $75 \%$ & & \\
\hline \multicolumn{4}{|l|}{ Grade of General English in G.C.E(A/L) } & 19.83 & & 0.07 \\
\hline \multicolumn{7}{|l|}{ Grade A } \\
\hline Grade B & $12.5 \%$ & $0 \%$ & $4.3 \%$ & $0 \%$ & & \\
\hline Grade C & $12.5 \%$ & $12 \%$ & $8.7 \%$ & $0 \%$ & & \\
\hline Grade S & $12.5 \%$ & $20 \%$ & $17.4 \%$ & $0 \%$ & & \\
\hline \multirow[t]{2}{*}{ Grade F } & $50 \%$ & $42 \%$ & $8.7 \%$ & $50 \%$ & & \\
\hline & $12.5 \%$ & $26 \%$ & $60.7 \%$ & $50 \%$ & & \\
\hline \multicolumn{5}{|l|}{ Usage of library } & 12.27 & 0.056 \\
\hline Never & $0 \%$ & $6 \%$ & $0 \%$ & $25 \%$ & & \\
\hline Some times & $75 \%$ & $88 \%$ & $100 \%$ & $75 \%$ & & \\
\hline Regularly & $25 \%$ & $6 \%$ & $0 \%$ & $0 \%$ & & \\
\hline
\end{tabular}

Source: Authors' calculation, 2018/2019

Other two variables related to the grade of general English in G.C.E (A/L) and usage of library have associated with the students' performance in microeconomics subject, but they were significant at $10 \%$ level. Harb \& El- Shaarawi (2007) and Sriyalatha (2016) found that student's competence level in English as the most significant factor to determine the students' performance. These finding is consistent with the current study. Thus, compared to these two aspects, family stress and frequency of study patterns for economics associate more with the academic performance in the given subject.

\section{Results of ordered probit regression model}

The ordered probit model focused on the demographic characteristics of the selected 85 undergraduate students in Vavuniya campus that influence on their performance in micro economics subject and its results are presented in table 6 .

The overall explanatory power of the estimated model is examined by the log likelihood test and it has negative value of 81.54 which implies that the null hypothesis of the explanatory variables equal to zero is rejected at $1 \%$ significance level. The goodness fit of the model is measured by the value of chi-square $\left(\chi^{2}\right)$ test statistic which is 12.37 which showed that, the model fits well and the choice of explanatory variables included in the ordered probit model are appropriate explaining the variation in the grades of the students in microeconomics subject. Gender of the student, whether the particular student has stress in his or her family, and the availability of the family members who have management degree were taken as the major variables for demographic characteristics of the students. Out of three variables, gender and family stress have strongly significant impact on performance of student and family members with management degree is insignificant in the model. The estimated coefficient on gender has positive value of 0.558 suggested that female students have more probability to obtain grade A than male students in the subject and it is statistically a significant at $5 \%$ level. The findings of Raychauduri et al. (2010) and McCarty et al. (2006) are in consistent with the present study 
Table 6: Results of ordered probit model for demographic and family background

\begin{tabular}{|c|c|c|c|}
\hline \multicolumn{2}{|l|}{ Log likelihood $=-81.54$} & \multicolumn{2}{|c|}{$\begin{array}{l}\text { Number of observations }=85 \\
\text { LR } \chi^{2}(6)=12.37 \\
\text { Probability }>\chi^{2}=0.0062 \\
\text { Pseudo } R^{2}=0.0705\end{array}$} \\
\hline$\overline{\text { Variables }}$ & Coefficient & Standard error & Significant \\
\hline Gender & 0.558 & 0.273 & 0.042 \\
\hline Family stress & -0.973 & 0.307 & 0.002 \\
\hline $\begin{array}{l}\text { Family members with } \\
\text { management degree }\end{array}$ & 0.015 & 0.304 & 0.959 \\
\hline
\end{tabular}

Source: Authors' calculation, 2018/2019

Table 7: Marginal effects of ordered probit model for demographic and family background

\begin{tabular}{lcccc}
\hline & \multicolumn{4}{c}{ Probability of getting } \\
\cline { 2 - 5 } Variables & Grade D & Grade C & Grade B & Grade A \\
\hline Gender & -0.032 & -0.151 & 0.088 & 0.095 \\
Family stress & 0.112 & 0.252 & -0.262 & -0.102 \\
Family members with & -0.001 & -0.004 & 0.003 & 0.002 \\
management degree & & & & \\
\hline
\end{tabular}

Source: Estimated by authors, 2018/2019

but they contradict with Muhammedhussen (2016) who found that gender as an insignificant factor to determine the students' performance.

The parameter estimate of the family stress with negative sign reveals that, the students who have stress in their family, the probability to get grade A will be lower than who don't have such types of stress in the family. In other words, the students who do not have family stress, can perform well in their educational activities and thus they are more likely to get grade A than others. Same finding is supported by Zajacova et al. (2005) while Mushtaq \& Khan (2012) found negative relationship between family stress and student performance but it was insignificant.

The positive coefficient of family members with management degree implied that, students who follow the degree with their family background encourages them to perform well and more possibility to get grade A than other students. But it is insignificant in the model. The overall results of the model proved that, gender has a significantly positive impact whereas family stress has strongly negative impact on the academic performance of the microeconomics subject among the selected first year students in the campus.
In addition to the above results, marginal effects are also estimated in the model and its results are shown in the table 7 .

The estimated average marginal probability effect of gender has -0.032 and -0.151 in grades D and $\mathrm{C}$ in the model implies that, female students have $3.2 \%$ and $15.1 \%$ of less probability to obtain grades $\mathrm{D}$ and $\mathrm{C}$ respectively, but they have $8.8 \%$ and $9.5 \%$ of more probability to get grades B and A respectively in the microeconomics. In another way, male students have $3.2 \%$ and $15.1 \%$ of more probability to obtain grades $\mathrm{D}$ and $\mathrm{C}$ while their probability to achieve the higher performance in terms of grades B and A will be lower by $8.8 \%$ and $9.5 \%$ respectively.

Marginal effect of family stress has positive signs for getting grades $\mathrm{C}$ and $\mathrm{D}$, but it has negative signs for grades $\mathrm{B}$ and $\mathrm{A}$ meaning that, even the students who face more family stress, their probability to obtain the grades D and C will be higher by $11.2 \%$ and $25.2 \%$ whereas, the probability of getting grades $\mathrm{B}$ and $\mathrm{D}$ will be less by $26.2 \%$ and $10.2 \%$ respectively. These results clearly imply that, family stress is one of the major obstacles to get the best results and adversely affect on students' performance in the microeconomics subject. In case of family background, a member 
Table 8: Results of ordered probit model for educational background

Number of observations $=85$

LR $\chi^{2}(6)=49.60$

Probability $>\chi^{2}=0.000$

Log likelihood $=-62.92$

Pseudo $R^{2}=0.2827$

\begin{tabular}{lccc}
\hline Variables & Coefficient & Standard error & Significance \\
\hline Allocation of time & 1.677 & 0.516 & 0.001 \\
Levels of attendance & 0.003 & 0.223 & 0.989 \\
Economics as subject in G.C.E(A/L) & 0.966 & 0.307 & 0.002 \\
Mathematics knowledge & 0.904 & 0.239 & 0.000 \\
Usage of library facilities & -0.664 & 0.354 & 0.061 \\
Available of own text book & 0.459 & 0.307 & 0.135 \\
\hline
\end{tabular}

Source: Estimated by authors, 2018/2019

with a management degree has motivated the students to earn more grades in their subject and, it was insignificant in the model.

Six explanatory variables taken as educational factors and their impact on getting probability of four different grades in microeconomics were also estimated using ordered probit model. Out of the six variables, levels of attendance to the lectures and available of having their own text book were not significantly determinants on the performance of the students while rest of other variables were the major determinants in the study.

Table 8 shows that among the educational factors, allocation of time, economics as subject in G.C.E(A/L) and mathematics knowledge have strongly influencing the students' performance in microeconomics whereas, usage of library by the students is significant at $10 \%$ level. Allocation of time has positive value of 1.677 implies that, the students who allocate their time more than two hours per day for studying in economics, the probability of getting grades also will be higher assumed that other factors held constant. The coefficients of economics as a subject in G.C.E (A/L) and mathematics knowledge have positive sign with significant levels proved that, the students who studied economics as one the subjects in G.C.E (A/L) and prior knowledge in mathematics help them to perform well and thus their probability to obtain grade A will be higher in microeconomics during their undergraduate study period than other students. Results of the studies of Heublein (2014) and Arnold \& Straten (2012) also found that mathematical knowledge as a key determinant in study performance in subjects.
Usage of library remains negative with significant level at $10 \%$ and it indicated that, the students who use the library facilities regularly, are more likely to get an A grade while the students who never use the library the probability to get lower grade $\mathrm{D}$ will be higher. This finding suggests that, library facilities and reading habits of the students are the important determinant in students' performance and they should encourage referring the additional study materials and books in the library. Wells (1995) found that a positive correlation between academic achievement and the use of a number of different library resources and services. Karemera et al. (2003) found significant relationship between library usage and students' performance.

In the present study, level of attendance found as an insignificant determinant of students' performance and this result contradict with the findings of Raychauduri et al. (2010), Sriyalatha (2016) and Ogweno et al. (2014). Further, Sattayanuwat (2015) found that higher level of attendance for the lectures and tutorial classes directed to increase the performance level.

Coefficients of ordered probit model can be expressed in terms of marginal effects and its results depicted in table 9 .

Marginal effects of allocation of time has negative impact on getting grades $\mathrm{D}$ and $\mathrm{C}$ while it has positive sign in grades B and A illustrates that, as the time for study increases more than two hours the probability of getting grades D and $\mathrm{C}$ will be lower by $3.5 \%$ and $49.7 \%$ whereas probability of getting grades B and A will be higher by $42.5 \%$ and $10.7 \%$ respectively. Therefore, if a student expects 
Table 9: Marginal effects of ordered probit model for educational background

\begin{tabular}{lcccc}
\hline \multirow{2}{*}{ Variables } & \multicolumn{4}{c}{ Probability of getting } \\
\cline { 2 - 5 } & Grade D & Grade C & Grade B & Grade A \\
\hline Allocation of time & -0.035 & -0.497 & 0.425 & 0.107 \\
Levels of attendance & -0.00006 & -0.0009 & 0.0007 & 0.0002 \\
Economics as subject in G.C.E(A/L) & -0.020 & -0.286 & 0.244 & 0.061 \\
Mathematics knowledge & -0.019 & -0.268 & 0.229 & 0.057 \\
Usage of library & -0.014 & 0.196 & 0.168 & 0.042 \\
Available of own text book & -0.012 & -0.141 & 0.128 & 0.025 \\
\hline
\end{tabular}

Source: Estimated by authors, 2018/2019

that to get good results in economics, he or she should spend more than two hours per day for that subject.

The students who studied economics as one of the subjects in G.C.E (A/L) has negative marginal effects in obtaining the grades D and C, but they have positive signs in grades $\mathrm{B}$ and $\mathrm{A}$ suggesting that, the students with a prior knowledge in economics have $2 \%$ and $28.6 \%$ of less likelihood to get grades $\mathrm{D}$ and $\mathrm{C}$, but their probability to get grades B and A will be more by $24.4 \%$ and $6.1 \%$ respectively.

The students who have a knowledge in mathematics, will better perform in microeconomics subject also. Because, compared to other subjects, microeconomics has more connection and interaction with maths. Due to this reason, the students with mathematics knowledge, have $22.9 \%$ and $5.7 \%$ of probability to get grades B and A respectively. Similarly, the students who use the library on a regular basis have $1.4 \%$ of less probability to get grade D, $19.6 \%$ of more likelihood to get grade C, $16.8 \%$ and $4.2 \%$ of more likelihood to get grades B and A respectively.

\section{Conclusion and Recommendations}

The study examined the determinants of performance in microeconomics subject among the students who are following the management degree in Vavuniya campus, Sri Lanka. A sample of 85 students were selected randomly from the first year first semester and the frequency of their grades showed that, only $9.4 \%$ of them received grade A while $4.7 \%$ of them got grade D. Majority of them got grade $\mathrm{B}$, followed by grade $\mathrm{C}$ in microeconomics during the first year first semester.

Comparing the students' grades among gender, the results found that female students performed better than males in microeconomics. Results of chi- square test revealed that, family stress faced by students, frequency of study was significantly associated with their performance in the subject. By applying an ordered probit model, estimated results proved that, among demographic characteristics and family background of the students, gender and family stress were the significant predictors of their performance. Marginal effects of the model showed that, family stress is one of the major problems faced by the students in performing well in the microeconomics subject. In case of educational background related to the study habits of the students revealed that, knowledge in mathematics, allocation of time to study microeconomics and whether the student already studied economics as one of the subjects in G.C.E (A/L) were the significant indicators on students' performance. When the students allocate more than two hours per day to study microeconomics, the probability of receiving grades $\mathrm{B}$ and $\mathrm{A}$ also increase by $42.5 \%$ and $10.7 \%$ respectively concluding that, there is a need to spend more time for economics subject to do well in exam. In case of library usage, it is not significant in the study which emphasises on the importance of students' grades. Thus, this study recommended that, motivating the students to use the library facilities and increasing their reading of additional books and own materials should be concerned to increase their grades and performance of th microeconomics. Further, this study recommended that supplementary courses are necessary to increase the students' performance in future. 


\section{References}

Ali, S., Haider, Z., Munir, F., Khan, H., and Ahmed, A. (2013). Factors contributing to the students' academic performance: A case study of Islamia University Sub-Campus. American journal of educational research, v.1 (8), pp. 283289. DOI: $10.12691 /$ education-1-8-3

Arnold, I. J., \& Straten, J. T. (2012). Motivation and math skills as determinants of first-year performance in economics. The Journal of Economic Education, v.43 (1), pp. 33-47. DOI: 10.1080/00220485.2012.636709

Breton, T. R. (2015). Human capital and growth in Japan: Converging to the steady state in a $1 \%$ world. Journal of the Japanese and International Economies, v.36, pp.73-89. DOI: 10.1016/j.jjie.2015.03.001

Chambers, E. A., \& Schreiber, J. B. (2004). Girls' academic achievement: varying associations of extracurricular activities. Gender and Education, 16(3), pp.327-346. DOI: $10.1080 / 09540250042000251470$

Harb N. \& El-Shaarwi A. (2007), Factors Affecting Students' Performance, Global Journal of Management and Business Research, v.12 (9). DOI: $10.3200 /$ joeb.82.5.282-290

Heublein, U. (2014). Student Dropout from G erman Higher Education Institutions. European Journal of Education, v.49 (4), pp.497-513. DOI: $10.1111 /$ ejed.12097

Johns, T. R., Yang, C. W., Chen, P. Y., Kim, P. Y., and Hung, K. (2007). An Ordered Probit Model for Understanding Student Performance in Operations Management. In Annual Conference on Pacific Basin Finance, Economics, Accounting and Management.

Karemera, D., Reuben, L. J., and Sillah, M. R. (2003). The effects of academic environment and background characteristics on student satisfaction and performance: The case of South Carolina State University's School of Business. College Student Journal, v.37 (2), pp.298-309.

McCarty, C., Padgham, G., and Bennett, D. (2006). Determinants of student achievement in principles of economics. Journal for Economic Educators, v.6 (2), pp.1-9.
Muhammedhussen, M. (2016). Determinants of Economics Students' Academic Performance: Case Study of Jimma University, Ethiopia. International Journal of Scientific and Research Publications, v.6 (1), pp.566-571

Mushtaq, I., \& Khan, S. N. (2012). Factors Affecting Students' Academic Performance. Global journal of management and business research, v.12 (9).

Ogweno P.O., Kathuri N. N. and Obara J. (2014) , Influence of Students Characteristics on Academic Performance in Secondary Agriculture, in Rachuonyo North Sub County, Kenya, International Journal of Education and Research, v.2 (3), pp.1-12. DOI: 10.21474/ijar01/897

Pretorius, A., Prinsloo, P., \& Uys, M. D. (2009). Student performance in Introductory Microeconomics at an African open and distance learning institution. Africa Education Review, 6(1), 140158. DOI: $10.1080 / 18146620902857574$

Raychaudhuri, A., Debnath, M., Sen, S., and Majumder, B. G. (2010). Factors affecting students' academic performance: A case study in Agartala municipal council area. Bangladesh. e- Journal of Sociology, v.7 (2), pp.34-41.

Sarwar, A. (2012). Factors having impact on the performance of business students. International Journal of Business and Social Science, 3(17).

Sattayanuwat W. (2015), Determinants of Student Performance in International Trade Course, American Journal of Educational Research, v.3 (11)

Sriyalatha, M. A. K. (2016). Factors Contributing to Students' academic Performance: A Case of University of Sri Jayewardenepura, Sri Lanka. Sri Lanka Journal of Business Economics, v.6 (1).

Wells, J. (1995). The influence of library usage on undergraduate academic success. Australian Academic \& Research Libraries, 26(2), pp.121128. DOI: $10.1080 / 00048623.1995 .10754923$

Zajacova, A., Lynch, S. M., and Espenshade, T. J. (2005). Self-efficacy, stress, and academic success in college. Research in higher education, 46(6), pp.677-706. DOI: $10.1007 / \mathrm{s} 11162-004-$ 4139-z 